\title{
Application of constitutive models in European codes to RC-FRC
}

\author{
Ana Blanco a*, Pablo Pujadas ${ }^{a}$, Albert de la Fuentea, Sergio Cavalaroa, Antonio Aguado ${ }^{a}$ \\ a Department of Construction Engineering, Universitat Politècnica de Catalunya, UPC, Jordi Girona 1-3, 08034 \\ Barcelona, Spain. \\ * Corresponding author. Tel.: +34-93-401-7347; fax: +34-93-401-1036; e-mail: ana.blanco@upc.edu
}

\begin{abstract}
The recent publication of codes for the design of FRC is a major step towards extending the use of the material. An in depth analysis indicates several differences between the constitutive models proposed in the existing codes. In this study, these models are compared and a numerical simulation is performed to evaluate their differences in terms of the structural behavior predicted and measured in an experimental program of RC-FRC elements. The predictions provided by the models fit satisfactorily the experimental results for elements with steel fibers and with plastic fibers
\end{abstract}

Key words: FRC, fiber, constitutive model, Model Code, design.

\section{Introduction}

Fiber reinforced concrete (FRC) is one of the most relevant innovations in the field of special concretes. In the last three decades, many studies were performed in order to understand better the mechanical properties of FRC. Nevertheless, the lack of international codes and guidelines for the design of FRC elements for many years hindered its expansion as a competitive structural solution. The use of FRC was then limited to the purpose of improving durability by means of cracking control and the structural contribution of fibers to the structural contribution was not considered.

The turning point regarding the incorporation of fibers as a reinforcing material took place gradually throughout the last ten years, after the publication of design codes and recommendations in Europe [1] (namely in order of appearance: the German code [2], the RILEM Scientific Committee 162 recommendations [3], the Italian guideline [4], the Spanish code [5] and the fib Model Code [6]). Hence, the increasing interest among civil engineers about the application of fibers as a reinforcement material.

In Spain, a clear example of this change is observed in the design of tunnels [7]. Although for many years such structures were designed with traditional reinforcement and steel fibers, the contribution of the latter to the post-cracking behavior of steel fiber reinforced concrete (SFRC) was not taken into account. The publication of the EHE-08 [5] led to consider the contribution of fibers and to the optimization of the amount of reinforcing bars (rebars) since, in some cases, the Spanish code allows the partial or total substitution of rebars for structural fibers ${ }^{1}$ [9]. This makes FRC and the combined solution of traditional reinforced concrete (RC) and FRC (hereinafter RC-FRC) a competitive design alternative both from the technical and the economic point of view [7-8, 10-11].

\footnotetext{
${ }^{1}$ Structural fibers are defined as those having a high modulus of elasticity and that, in a certain dosage, are able to guarantee minimum FRC performance in terms of toughness [8]. Recently published codes such as CNR-DT 204, EHE-08 and fib Model Code distinguish between nonstructural fibers and structural fibers due to the great importance that this change in terminology has on the application of fibers.
} 
In order to design FRC structures it is essential to have solid, rational and reliable models to reproduce the behavior of FRC as indicated in [12]. A in depth analysis indicate several differences between the constitutive models proposed in codes to design FRC structures. The first step to reach an agreement has been taken by the Technical Group fib TG 8.3 "Fiber reinforced concrete" and TG 8.6 "Ultra high performance fiber reinforced concrete" in the New Model Code [6], a document that is the reference for Eurocode 2 and other guidelines at a national level.

Given the variety of the existing constitutive models, this document aims at reviewing the main studies, standards and recommendations that are currently being used to design FRC, focusing mainly on the fib Model Code 2010 [6], considered as a reference for future guidelines. Furthermore, a numerical simulation is performed to evaluate their differences in terms of the structural behavior predicted using the model AES [14] and measured in the experimental program presented in [13]. The results of this study contribute to the understanding of FRC in the scope of structural design and help extend its use among professionals.

\section{Constitutive models from the literature}

There are numerous constitutive models proposed in the literature for the design of FRC based on either stress-strain $(\sigma-\varepsilon)$ curves or stress-crack width $(\sigma-w)$ curves. Most of these models are based on an indirect approach, requiring parameters that must be defined each time from experimental data. Less common are the models based on a direct approach that provides the same curves using basic properties of its constituent materials [15]. The differences of using $\sigma-w$ and $\sigma-\varepsilon$ models are discussed in the following section. Subsequently, some of the models proposed in the literature are presented grouped by the approach used (indirect or direct).

\subsection{Stress-crack width $(\sigma-w)$ and stress-strain $(\sigma-\varepsilon)$ models}

The tensile behavior of FRC can be defined by means of a $\sigma$ - $w$ diagram or a $\sigma-\varepsilon$ diagram. Both approaches, despite presenting advantages and drawbacks, are accepted in the most recent recommendation for the design of FRC (the Model Code 2010 [6]).

The $\sigma-w$ diagram is based on the concept of the Fictitious Crack Model (FCM) of Hillerborg et al. [16], which states that a stress-displacement $(\sigma-\delta)$ relationship can be split into a $\sigma-\varepsilon$ relation for the linear-elastic behavior of the concrete outside the crack and $\sigma$ - $w$ relation for the softening behavior in the cracked section. The main advantage of using a $\sigma-w$ model is that it can be directly compared to the experimental results (e.g. uniaxial tensile tests), thus providing actual physical insight of the mechanisms occurring in the FRC [15].

With the $\sigma-\varepsilon$ model the tensile and the compressive behaviors may be represented in a single diagram. Likewise, such approach is more convenient for practical reasons since it is the same used for traditional steel reinforcement.

Notice that there are several studies in the literature dedicated to the relation between the $\sigma$ - $w$ diagram and the $\sigma-\varepsilon$ diagram, using characteristic length $\left(I_{c s}\right)$ [17-19].

\subsection{Indirect approach}

Among the several constitutive models following an indirect approach, one of the first proposals regarding a $\sigma-\varepsilon$ curve for FRC was presented in [20]. In this model, the authors considered that, in the case of a low content of fibers, the contribution of fibers on the precracking behavior could be assumed as negligible and suggested a constant post-cracking 
branch [21], as can be seen in Fig. 1a. Another model proposed in [22] introduced a nonlinear relationship in the pre-cracking stage (depicted in Fig. 1b). In order to achieve a better estimation of the fiber contribution to the post-cracking regime, an intermediate branch was added before the final constant branch. A study of great relevance was performed by Dupont and Vandewalle [23]. In this case, the authors proposed a $\sigma-\varepsilon$ diagram with two levels of stress (Fig. 1c) that are characteristic of the strains $\varepsilon_{2}=2.5 \% 0$ and $\varepsilon_{3}=15 \%$, leading to a post-cracking stage independent from the concrete tensile strength. According to the authors, this two-level approach is justified by the fact that fibers need to deform previously to the bridging of the cracks.
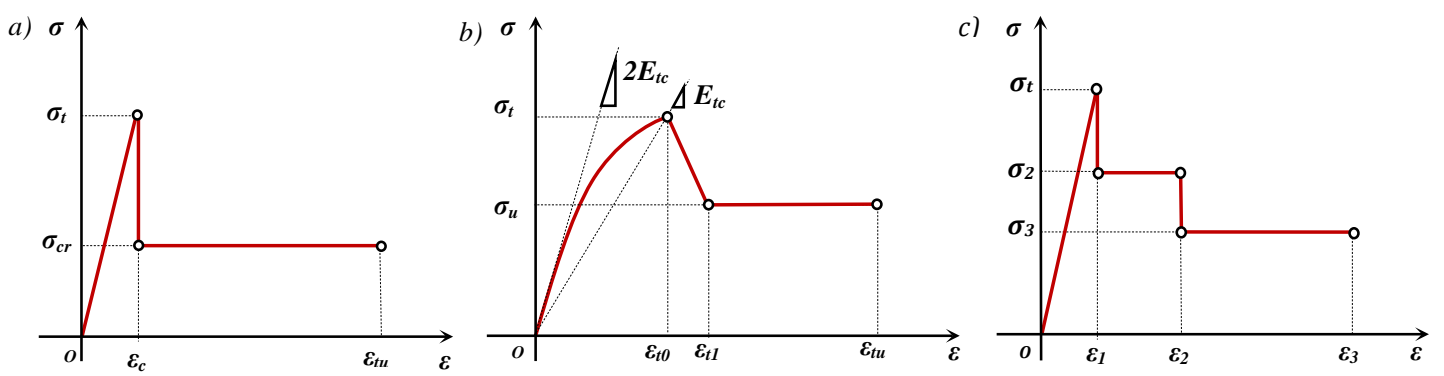

Fig. 1. Constitutive models $(\sigma-\varepsilon)$ for the characterization of the tensile behavior of FRC [20, 22, 23].

There are also several proposals concerning models based on a $\sigma-w$ diagram. The model presented in [24] consists of a bilinear curve (Fig. 2a) whose parameters are defined by means of an inverse analysis. An alternative model was proposed in [25] that considers a trilinear curve and an increasing residual strength with crack width up to $2 \mathrm{~mm}$ (Fig. 2b). Later studies conducted by di Prisco [26] led to the proposal of a $\sigma-w$ bilinear model (Fig. 2c), with a first softening stage related to the cracking of the matrix. The contribution of the fibers is considered in the second stage and is defined by two average stresses at certain crack widths. Dozio [27] found out that this model overestimates the crack width that marks the intersection between the first and the second post-cracking branches and proposed a modified bilinear model.
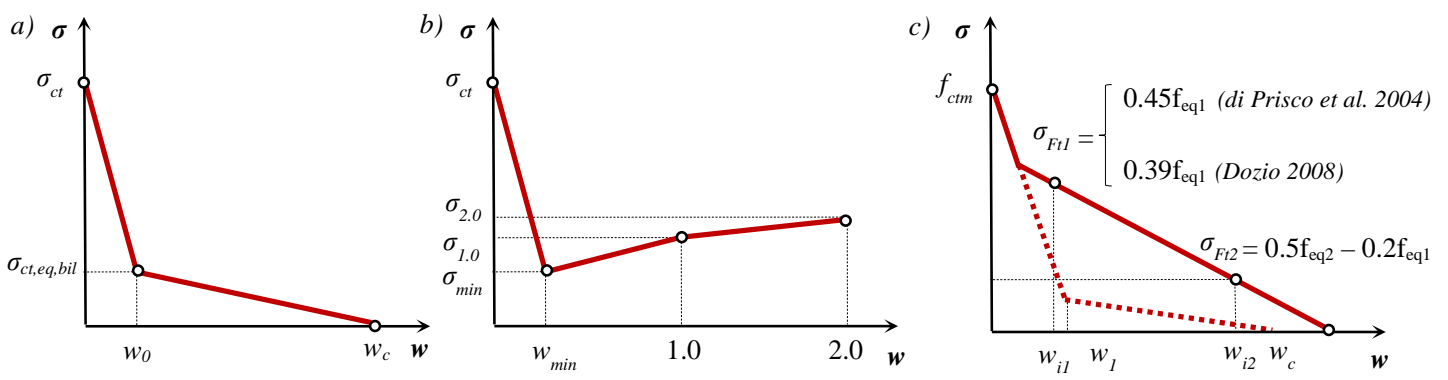

Fig. 2. Constitituve models ( $\boldsymbol{\sigma}-\boldsymbol{w})$ for the tensile behavior of FRC [24-27].

\subsection{Direct approach}

The use of a direct approach to simulate the uniaxial behavior of the material requires the definition of parameters defining the constitutive relation [15], which may be determined either from experimental data or from specific material properties. The models presented subsequently are based on the prediction of the fiber pullout and the contribution of the matrix. 
The relevance of the study by Li et al. [28] lies in the approach followed to propose a $\sigma$ - $w$ constitutive model (see Fig. 3a). The authors considered the physical mechanics that governs the cracking of FRC and introduced several concepts such as the softening relation for the plain concrete, the number of fibers crossing the crack, the single fiber pullout behavior, the orientation and the distribution of fibers. The large number of parameters involved and the limited range of applicability (only up to $0.3 \mathrm{~mm}$ ) hindered its application.

Prudencio et al. [29] present an approach where the average pullout response of the fibers bridging the cracked zone is inferred from flexural tests. A stress-block approach is used to represent the stresses that develop at a cracked section. In order to predict the moment capacity, the load-crack mouth opening relation for a particular FRC is used in the stressstrain profile in the flexural analysis. A similar approach is presented in [30], where a semi-analytical model is proposed to predict the flexural response of SFRC. This model also uses a stress-block approach and relates the flexural capacity of the critical section to the following parameters: the compressive stress-train relation, the tensile stress-strain relation, the fiber pullout, the number and distribution of the fibers across the cracked section (in terms of position, orientation and embedment lengths) as well as the strain/crack width relation at a given mid-span deflection.

In the study by Laranjeira [15], a design-oriented $\sigma$ - $w$ constitutive model is proposed. This constitutive model is in the sum of two main contributions: plain concrete post-cracking strength and overall steel fiber pullout strength (see Fig. 3b). This model also takes into account the properties of the FRC components, the production processes and some characteristics of the structure to be built. The input parameters in this model are: the characteristic compressive strength, the diameter, the length, the tensile yield strength of the fiber as well as its volume content, the cross section of the structure to be design and the fiber orientation number.

a)

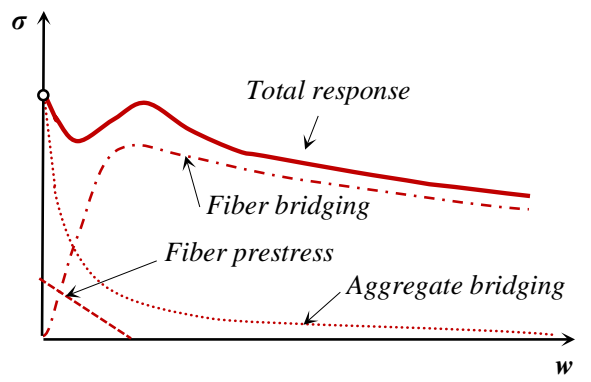

b)

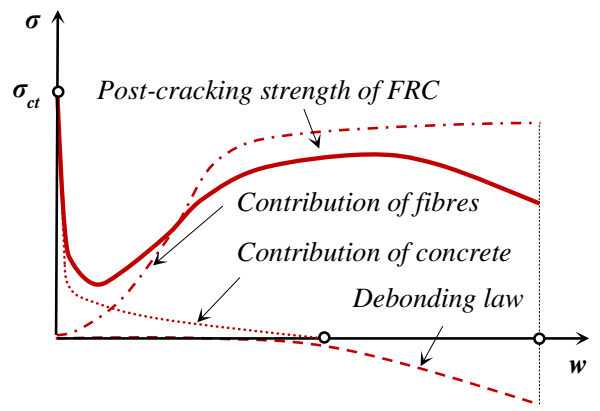

Fig. 3. Constitutive models $(\boldsymbol{\sigma}-\boldsymbol{w})$ for the tensile response of FRC [28 and 15].

A recent study by Luccioni [31] presents an interesting approach based on modified mixture theory to model SFRC. The authors propose to model concrete with an elastoplastic model and the steel fibers as orthotropic elastoplastic inclusions that exhibit debonding and slipping from the matrix. For that purpose, the constitutive equations of fibers are modified to include the debonding-slipping phenomena. The input parameters of this model are: concrete properties, fibers material, geometry, distribution and orientation. Concrete properties and fiber geometry are used to obtain the bond-slip response of the fibers. Alternatively, this information may be obtained from pullout tests. 


\section{Constitutive models in European codes and recommendations}

\subsection{Identification of the models}

The identification of the most suitable constitutive model to simulate the tensile postcracking behavior represents one of the key steps in the design of FRC structures. Over the past ten years several technical guidelines have been published with the aim of facilitating the design of these structures [32-33]. Table 1 presents the constitutive models proposed by European standards [2-6] grouped according to the type of diagram (namely rectangular, bilinear and trilinear or multilinear). The same table also summarizes the main parameters that define each one of the models and includes the schematics of the tests required to obtain the values of these parameters 


\begin{tabular}{|c|c|c|c|c|}
\hline & Diagram & Parameters & Characterization test & \\
\hline \multirow{4}{*}{$\sigma_{1} \sigma_{1} \uparrow$} & \multirow{4}{*}{$\stackrel{\varepsilon_{1}}{\longrightarrow} \boldsymbol{\varepsilon}$} & $\begin{array}{l}\sigma_{1}=f_{\text {eq, }, t d, I I}=f_{\text {eq,ctk,II}} \cdot \alpha_{c} f \cdot \alpha_{s y s} / \gamma_{c t} f \leq f_{\text {eq, }, c t d, I} \\
\left(\alpha_{s y s:} \text { coefficient for size effect; } \alpha_{c}^{f}: \text { coefficient }\right. \\
\text { for longterm strength behaviour }) \\
\varepsilon_{1}=\varepsilon_{u}=10 \% 0\end{array}$ & 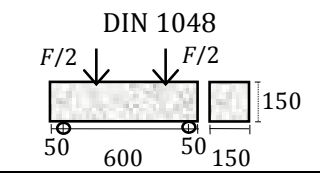 & 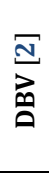 \\
\hline & & $\begin{array}{c}\sigma_{1}=f_{F t u}=f_{e q 2} / 3 \\
\varepsilon_{1}=\varepsilon_{u}=[20 \% \text { softening ; } 10 \% \text { hardening }]\end{array}$ & 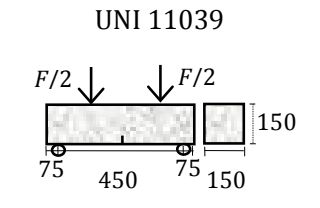 & 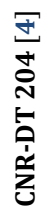 \\
\hline & & $\begin{array}{c}\sigma_{1}=f_{c t R d}=0.33 f_{R, 3, d} \\
\varepsilon_{1}=\varepsilon_{u}=[20 \% \text { bending; } 10 \% \text { tensile }]\end{array}$ & 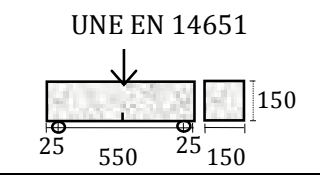 & 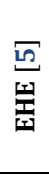 \\
\hline & & $\begin{array}{c}\sigma_{1}=f_{F t u}=f_{R 3} / 3 \\
\varepsilon_{1}=\varepsilon_{u}=[20 \% \text { of softening ; } 10 \% \text { o hardening }]\end{array}$ & 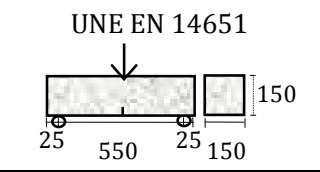 & $\frac{\sigma}{\grave{E}}$ \\
\hline \multirow{2}{*}{$\begin{array}{l}\sigma \\
\sigma_{1} \\
\sigma_{2} \\
\end{array}$} & & $\begin{array}{c}\sigma_{1}=f_{e q, c t d, I}=f_{e q, c t k, I} \cdot \alpha_{c} f \cdot \alpha_{s y s} / \gamma_{c t} \\
\sigma_{2}=f_{e q, c t d, I I}=f_{e q, c t k, I} \cdot \alpha_{c} \cdot \cdot \alpha_{s y s} / \gamma_{c t} \leq f_{e q, c t d, I} \\
\varepsilon_{2}=\varepsilon_{u}=10 \% 0\end{array}$ & 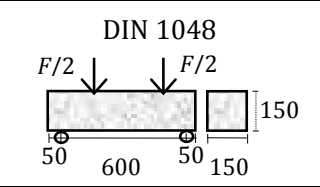 & 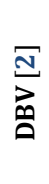 \\
\hline & $\overrightarrow{\varepsilon_{2}} \underset{\boldsymbol{\varepsilon}}{\longrightarrow}$ & $\begin{array}{c}\sigma_{1}=f_{\text {Fts }}=0.45 f_{\text {eq } 1} \\
\sigma_{2}=f_{\text {Ftu }}=k\left[f_{\text {Fts }}-\left(w_{u} / w_{\text {i2 }}\right)\left(f_{\text {Fts }}-0.5 f_{\text {eq } 2}+0.2 f_{\text {eq } 1}\right)\right] \\
k=[0.7 \text { pure tension, } 1 \text { other cases }] \\
\varepsilon_{2}=\varepsilon_{u}=[20 \% \text { softening; } 10 \% \text { o hardening }]\end{array}$ & 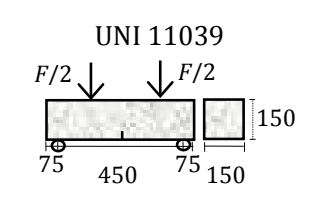 & 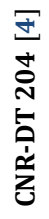 \\
\hline \multirow{2}{*}{$\begin{array}{l}\sigma \\
\sigma_{1} \\
\sigma_{2} \\
\sigma_{3}\end{array}$} & & 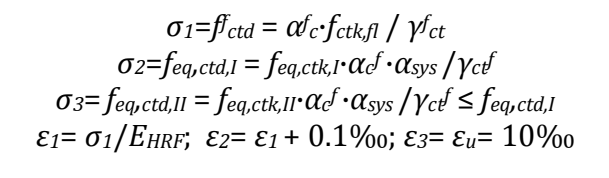 & 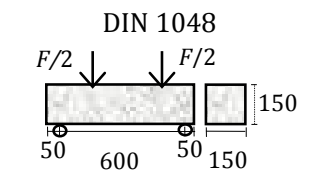 & $\frac{\mathfrak{N}^{\mathrm{N}}}{\mathrm{m}^{\circ}}$ \\
\hline & $\varepsilon_{3}$ & $\begin{array}{c}\sigma_{1}=0.7 f_{c t m, f l}(1.6-d) \\
\sigma_{2}=0.45 \cdot \kappa_{h} \cdot f_{R, 1} \\
\sigma_{3}=0.37 \cdot \kappa_{h} \cdot f_{R, 4} \\
\varepsilon_{1}=\sigma_{1} / E_{H R F} ; \varepsilon_{2}=\varepsilon_{1}+0.1 \% 0 ; \varepsilon_{3}=\varepsilon_{u}=25 \% 0\end{array}$ & 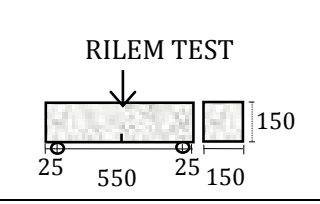 & $\frac{\sum_{i=1}^{\bar{m}}}{\overline{\underline{x}}}$ \\
\hline$\sigma \uparrow$ & $\begin{array}{lllll} & & & & \\
\varepsilon_{2} & \varepsilon_{3} & \varepsilon_{u} & \boldsymbol{\varepsilon}\end{array}$ & $\begin{array}{c}\sigma_{1}=f_{c t, d}=0.6 f_{c t, f l, d} \\
\sigma_{2}=f_{c t R 1, d}=0.45 f_{R, 1, d} \\
\sigma_{3}=f_{c t R 3, d}=\mathrm{k}_{1}\left(0.5 f_{R, 3, d}-0.2 f_{R, 1, d}\right) \\
\varepsilon_{2}=0.1+1000 \cdot f_{c t, d} / E_{c, 0} \\
\varepsilon_{3}=2.5 / l_{c s}\left(l_{c s}: \text { characteristic length }\right) \\
\varepsilon_{u}=[20 \% \text { bending; } 10 \% \text { pure tension }]\end{array}$ & 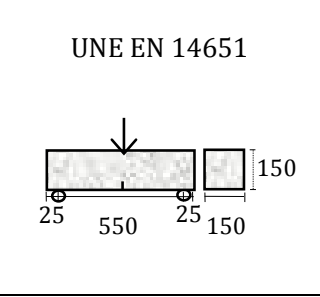 & 돈 \\
\hline $\begin{array}{r}\sigma \\
*_{F t u} \\
f_{F F t s} \\
f_{c t} \\
0.9 f_{c t} \\
f_{F t s} \\
f_{F t u}\end{array}$ & S\%o & $\begin{array}{c}f_{c t m}=f_{c t k 0, m}\left(f_{c k} / f_{c k 0}\right)^{2 / 3} \\
f_{F t s}=0.45 f_{R 1} \\
f_{F t u}=k\left[f_{F t s}-\left(w_{u} / C M O D_{3}\right)\left(f_{F t s}-0.5 f_{R 3}+0.2 f_{R 1}\right)\right] \\
\varepsilon_{S L S}=\mathrm{CMOD}_{1} / l_{c s} \\
\varepsilon_{S L U}=w_{u} / l_{c s}=\min \left(\varepsilon_{F u}, 2.5 / l_{c S}=2.5 / y\right) \\
\varepsilon_{F u}=[20 \% \text { softening; } 10 \% \text { hardening }]\end{array}$ & 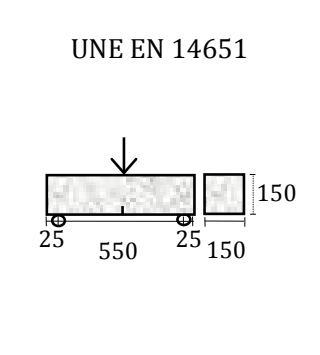 & $\frac{\sigma}{\underline{v}}$ \\
\hline
\end{tabular}

Table 1. Constitutive models in European guidelines. 
In Table 2, the criteria considered in each of the constitutive models introduced in Table 1 are presented. The models are listed according to the chronological order of publication, starting with the DBV [2], RILEM [3], CNR-DT 204 [4], EHE-08 [5] and ending with the fib Model Code [6]. Further detail on the DBV [2], RILEM [3], CNR-DT 204 [4] and EHE-08[5] may be found in [34].

\begin{tabular}{|l|c|c|c|c|c|}
\cline { 2 - 6 } & & & & & \\
\end{tabular}

Table 2. Characteristics of the constitutive models from guidelines.

One of the main differences between the first design guidelines (DBV [2] and RILEM [3]) and the newer ones is that the former only refer to steel fibers whereas the latter differentiate structural and non-structural fibers. This terminology implies a significant change in the design of FRC since it extends the range of fibers that may be used with structural purposes. Another common concept in the early design guidelines is the size effect. This concept takes into account the effect of the height on the bending behavior of the cross section by penalizing the section with larger height.

Another substantial difference among the design guidelines is the use of the equivalent flexural tensile strength $\left(f_{e q}\right)$ or the residual flexural tensile strength $\left(f_{R}\right)$ to obtain the parameters of the constitutive model. The parameter $f_{e q}$ is related to the energy absorption capacity of the material up to a certain deflection while the parameter $f_{R}$ corresponds to the stress associated to the force at a certain deflection. A study by Barros et al. [35] revealed that $f_{R}$ is more susceptible to local irregularities of the load-displacement curve, thus supporting the use of $f_{e q}$ instead. However, as indicated in Table 2, the general trend is to use $f_{R}$.

In the following section, the focus is set on the new fib Model Code [6] since is the more recent design guideline, being the document of reference for Eurocode 2 and other national guidelines. 


\section{2 fib Model Code (2010)}

The deeper knowledge gained on FRC over the past twenty years and the recent publication of design codes and guidelines at a national level led the fib (Fédération Internationale du Béton) to introduce FRC in the updated version of the CEB-FIP Model Code 90, with the aim of providing a tool for the design of FRC structural elements [36]. The fib Model Code proposes two models for the tensile behaviour of FRC: the rigid-plastic and the linear-elastic behavior (see Fig. 4). These models are presented in terms of simplifed $\sigma-w$ constitutive laws and reproduce materials with hardening and softening behavior.

a)

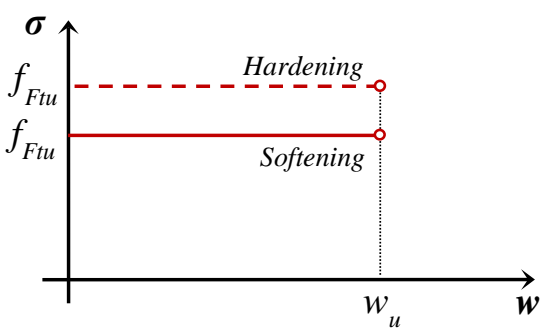

b)

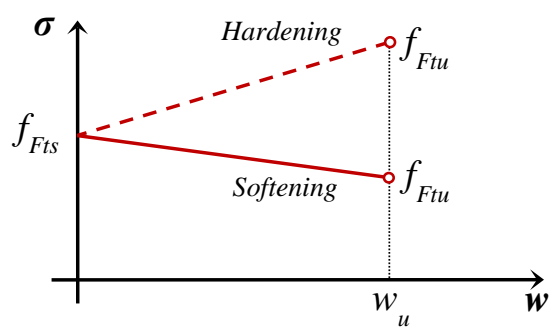

Fig. 4. Simplified constitutive laws ( $\boldsymbol{\sigma}$-w): a) Rigid-plastic and b) linear-elastic.

The parameters in both diagrams are defined by means of residual flexural tensile strengths, determined in the 3-point bending test EN 14651:2005. The parameter $f_{F t s}$ represents the serviceability residual strength defined as the post-cracking strength for crack openings at SLS. On the other hand $\boldsymbol{f}_{\text {Ftu }}$ represents the ultimate residual strength associated to the ULS crack opening $\mathbf{w}_{u}$, which is the maximum crack opening accepted in structural design. For the rigid-plastic model the value of $\mathbf{w}_{u}$ is $2.5 \mathrm{~mm}$, whereas for the linear-elastic model itdepends on the ductility required. The equations to determine the parameters $\boldsymbol{f}_{\text {Fts }}$ and $\boldsymbol{f}_{\text {Ftu }}$ are presented in Table $\mathbf{1}$. Since these two models are simplifications, the fib Model Code recommends the use of more advanced constitutive laws for numerical analysis (including the first crack tensile strength).

In order to define the stress-strain constitutive laws $(\sigma-\varepsilon)$ it is necessary to distinguish between softening materials and hardening materials. A material is regarded as strain hardening if it shows hardening behavior in tension up to an ultimate strain $\varepsilon_{\mathrm{Fu}}=1 \%$. Otherwise the material is considered as strain softening.

For softening materials, the $\sigma-\varepsilon$ law is defined by identifying the crack width and the corresponding structural characteristic length $\left(I_{c s}\right)$ of the structural element. Hence, the strain can be expressed as $\varepsilon=w / l_{c s}$. The characteristic length $l_{c s}$ is evaluated as:

$$
\mathrm{l}_{c s}=\min \left\{s_{r m}, y\right\}
$$

The parameter $\boldsymbol{S}_{r m}$ is the average crack spacing and $y$ is the distance between the neutral axis and the tensile side of the cross section. In the case of elements with conventional reinforcement, $y$ is evaluated in the cracked phase assuming no tensile strength of the FRC and a load configuration corresponding to the SLS of crack opening and crack spacing (see Fig. 5a). In sections without traditional reinforcement under bending or under combined tensile-flexural and compressive-flexural forces with the resulting force external to the section, the value of $y$ is assumed equal to the height of the section (see Fig. 5b). Notice that the use of the characteristic length is not necessary for hardening materials. 
a)

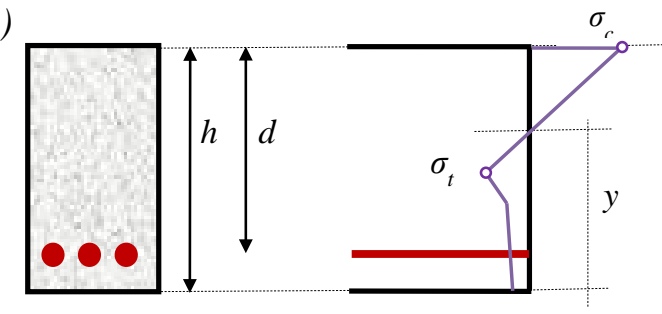

b)

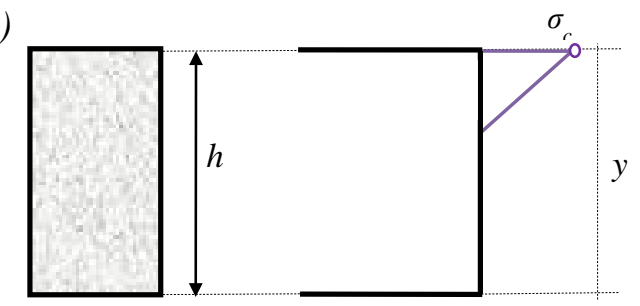

Fig. 5. Definition of the parameter " $y$ " for a) sections with traditional reinforcement and b) section without traditional reinforcement.

Once introduced the concept of characteristic length, it is important to remark that the the ultimate crack width $w_{u}$ required to estimate $f_{F t u}$ may be calculated as $w_{u}=l_{c s} \cdot \varepsilon_{F u}$. The ultimate strain $\varepsilon_{F u}$ equals $2 \%$ for variable strain distribution along the cross section and $1 \%$ for tensile strain distribution along the cross section. This is valid for softening or hardening materials.

The resulting $\sigma-\varepsilon$ relations are presented in Table 1. For materials with a softening behavior, the second branch suggested in the pre-cracking stage corresponds to the constitutive law for plain concrete until the intersection between the residual postcracking behavior and the unstable crack propagation occurs. This stretch is indicated as "MC90 Plain concrete" in Table 1. If the intersection does not occur due to the hardening behavior of the material, another branch is proposed (see dashed line in Table 1).

Regarding the characterization of the tensile behavior, although the bending test EN 14651:2005 [37] is recommended, other tests may be accepted if proven correlation factors with the parameters of EN 14651:2005 are used. In this sense, the fib Model Code advises not to use uniaxial tensile tests for standard testing of new mixtures due to the associated difficulty of execution and interpretation. Additionally, a proper consideration of the long-term behavior of cracked FRC under tension is required for those structural fibers whose long-term performance is influenced by creep (such as organic or natural fibers). Following the example set by the CNR-DT 204 [4] and EHE-08 [5], the fib Model Code specifies that fiber reinforcement can partially or totally substitute conventional reinforcement at ULS if certain requirements about the characteristic residual strengths and the limit of proportionality (as defined in EN 14651) are fulfilled.

The Model Code also presents partial safety factors for materials and an orientation factor $(K)$ for the design. This factor equals 1 if an isotropic fiber distribution is assumed and may be lower or higher than 1 if favorable or unfavorable effects are experimentally verified. This is a rather innovative approach since none of the previous guidelines accounted for the influence of fiber orientation due to casting, compaction or concrete consistency in the design. Moreover the Model Code is the first to suggest the execution of special tests to determine the effect of fiber orientation in structural specimens that are representative of the material in the structural element.

\section{Experimental program}

The elements tested are simply-supported slabs with a length of $3 \mathrm{~m}$, a width of $1 \mathrm{~m}$ and a height of $0.2 \mathrm{~m}$. These slabs have a combined reinforcement consisting of a conventional reinforcement and fibers (except in the case of two control elements which are only reinforced with conventional reinforcement). The conventional reinforcement is made up of seven bars with a diameter of $16 \mathrm{~mm}$ in longitudinal direction and bars with a diameter of $8 \mathrm{~mm}$ every $20 \mathrm{~cm}$ in transversal direction (B500S) as depicted in Fig. 6. The concrete cover of the longitudinal and transversal reinforcement is $35 \mathrm{~mm}$ and $50 \mathrm{~mm}$, respectively. 

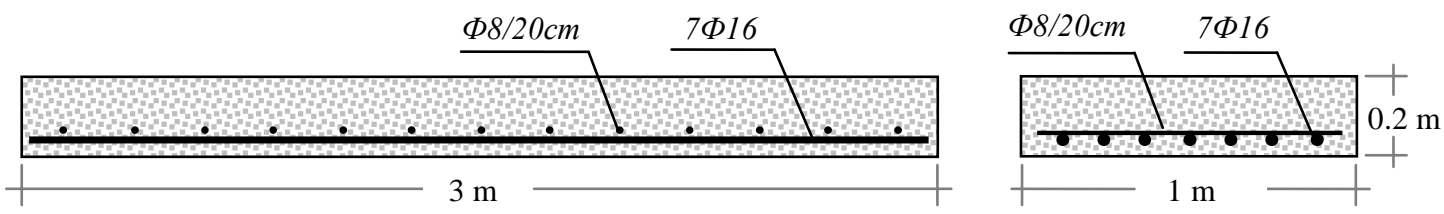

Fig.6. Conventional reinforcement in the slabs.

In addition to the conventional concrete slabs, eight types of FRC were prepared varying the types and contents of fiber ${ }^{2}$. The strength class of the fiber reinforced concrete was $\mathrm{C} 25 / 30$. The fiber content in the elements with mixed reinforcement is $0.25 \%$ of the total volume (which corresponds to $20 \mathrm{~kg} / \mathrm{m}^{3}$ of steel fibers and $2.28 \mathrm{~kg} / \mathrm{m}^{3}$ of polypropylene) and $0.50 \%$ of the total volume $\left(40 \mathrm{~kg} / \mathrm{m}^{3}\right.$ of steel fibers and $4.55 \mathrm{~kg} / \mathrm{m}^{3}$ of polypropylene fibers). Although two types of hooked-end steel fibers (SF) glued in bundles and two types of polypropylene fibers (PF) were used, for the purpose of this study only the results of elements with one type of SF and PF will be considered. The characteristics of both types of fibers are shown in Table 3.

\begin{tabular}{lcc}
\hline \multicolumn{1}{c}{ Characteristics } & SF & PF \\
\hline Length (mm) & 60 & 55 \\
Equivalent diameter (mm) & 0.75 & 0.80 \\
Aspect ratio & 80 & 70 \\
Tensile strength (MPa) & 1050 & 300 \\
Modulus of elasticity (GPa) & 210 & 3.0 \\
Number of fibers per kg & 4600 & 39000 \\
\hline
\end{tabular}

Table 3. Fiber characteristics (data provided by the manufacturer).

The notation used to refer to the slabs will be SF or PF depending on the type of fiber and $0.25 \%$ or $0.50 \%$ to indicate its content (e.g. SF_0.25\% or PF_0.50\%). The control slabs (without fibers) will be referred as RC. The material properties of the FRC are shown in Table 4. The compressive strength was determined according to European standard EN 12390-3:2009 [38] and the residual flexural tensile strength according to the EN 14651:2005 [37].

\begin{tabular}{|c|c|c|c|c|c|c|c|c|c|}
\hline & \multirow{2}{*}{$\begin{array}{l}\mathrm{RC} \\
f_{c m}\end{array}$} & \multicolumn{4}{|c|}{ SF_0.25 } & \multicolumn{4}{|c|}{ PF_0.25 } \\
\hline & & $f_{c m}$ & $f_{L}$ & $f_{R, 1}$ & $f_{R, 4}$ & $f_{c m}$ & $f_{L}$ & $f_{R, 1}$ & $f_{R, 4}$ \\
\hline Average (MPa) & 22.0 & 29.00 & 3.35 & 2.96 & 3.1 & 29.0 & 2.61 & 0.83 & 0.39 \\
\hline$\sigma(\mathrm{MPa})$ & 1.50 & 1.50 & 0.17 & 0.67 & 0.82 & 1.89 & 0.19 & 0.18 & 0.08 \\
\hline \multirow[t]{3}{*}{$\operatorname{cov}(\%)$} & 6.82 & 5.17 & 5.19 & 22.50 & 26.56 & 6.45 & 7.36 & 21.47 & 20.74 \\
\hline & & \multicolumn{4}{|c|}{ SF_0.50 } & \multicolumn{4}{|c|}{ PF_0.50 } \\
\hline & & $f_{c m}$ & $f_{L}$ & $f_{R, 1}$ & $f_{R, 4}$ & $f_{c m}$ & $f_{L}$ & $f_{R, 1}$ & $f_{R, 4}$ \\
\hline Average (MPa) & & 26.0 & 3.12 & 3.93 & 4.62 & 32.0 & 3.51 & 1.15 & 0.97 \\
\hline$\sigma(\mathrm{MPa})$ & & 1.89 & 0.37 & 0.69 & 0.93 & 1.53 & 0.22 & 0.27 & 0.29 \\
\hline $\operatorname{cov}(\%)$ & & 7.33 & 11.91 & 17.56 & 20.07 & 4.75 & 6.13 & 23.32 & 30.47 \\
\hline
\end{tabular}

Table 4. Compressive strength and residual flexural tensile strengths.

\footnotetext{
2 Despite the fact that fibers reduce the workability of concrete, in this case it was not considered necessary to modify the concrete mix since the workability shown by both types of concrete (RC and FRC) was similar.
} 
The values of average compressive strength and average flexural tensile strength present a relatively low scatter. Nevertheless, the values of residual flexural strength of the four series present a high scatter, above $20 \%$ in almost all cases, as is expected to occur for low-medium dosages of fibers [39-40]. The latter is related with the number of fibers crossing the relatively small failure plane

The beams were simply supported with a $2700 \mathrm{~mm}$ span and subjected to a four-point loading (see Fig. 7). The deflection at midspan as well as the crack width and spacing were measured in the constant moment zone of $900 \mathrm{~mm}$.

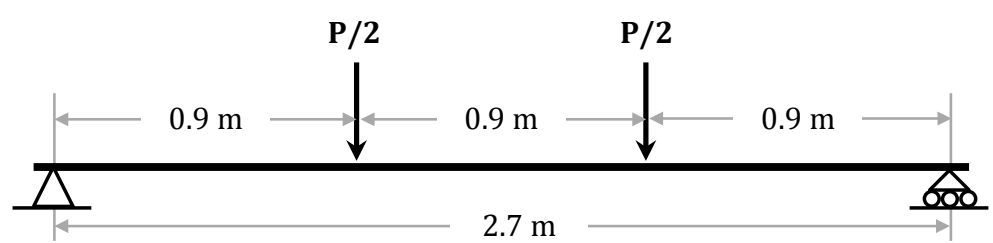

Fig. 7. Test setup.

Regarding the material shrinkage, given that the experimental program focused on the instantaneous response of RC-FRC, no tests were performed to measure this property. Anyhow, a visual inspection of the elements did not show any indication of strain or cracking due to shrinkage. Further detail on the experimental results, particularly regarding crack width and crack spacing may be found in [13].

\section{Numerical model to simulate the tests}

\subsection{Introduction}

In order to simulate the tests performed in the experimental program, a model capable of carrying out a non-linear sectional analysis and accounting for the cracking, post-cracking and post-failure behavior of the materials is required. With this purpose, the model AES (Analysis of Evolutionary Sections) presented in [14] was used. Likewise, a numerical subroutine for the structural analysis of the slabs, which includes the AES model, was also developed in this work. Such subroutine allows assessing the behavior of the slabs with several combinations of reinforcements under the test setup conditions.

In this section the main basis and hypothesis implemented in both models are presented aiming at giving a general overview on how these two numerical tools were conceived.

\subsection{Numerical simulation of the sectional behavior}

\section{Modeling stress-strain behavior of the materials}

The concrete is discretized in layers with constant thickness, whereas steel rebars are simulated as concentrated-area elements. Subsequently, the suitable constitutive model is assigned to each element in order to integrate the stresses resulting from a given deformation plane defined by a strain of a reference layer $\left(\varepsilon_{o}\right)$ and the curvature of the section $(\chi)$ (see Fig. 8a). 


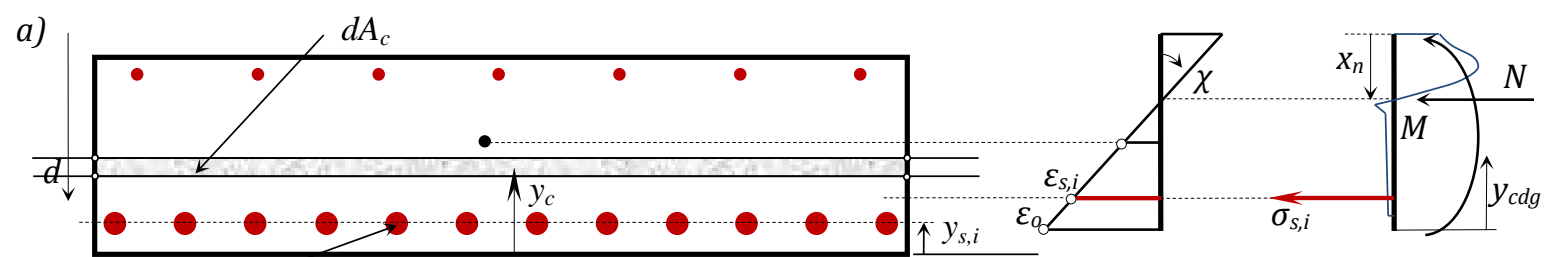

$A_{\mathrm{s}, i}$
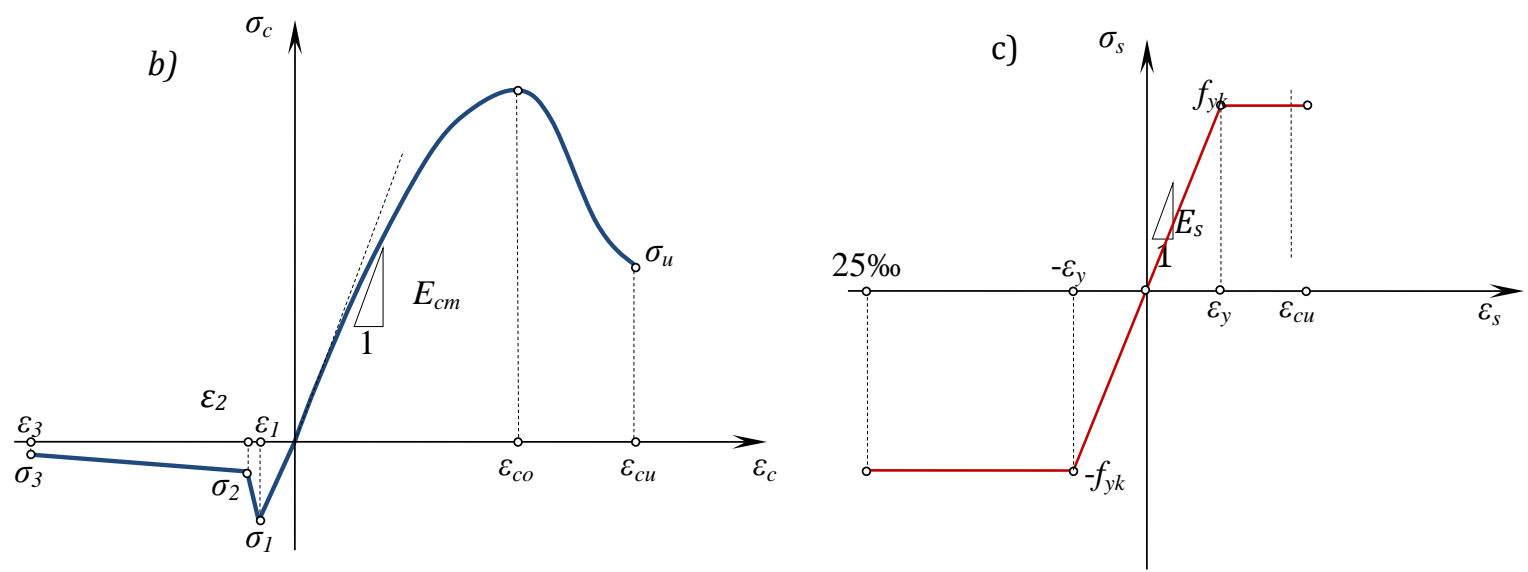

Fig. 8. (a) Sectional discretization; (b) FRC and (c) steel bar constitutive equations

The response of FRC under uniaxial compression is simulated with the expression suggested by Barros and Figueiras [41]. On the other hand, the simulation of the postcracking behaviour was performed separately with each model from Table 1.

The assessment of the crack width $(w)$ depends on the type of reinforcement of the section. For RC sections the formulation proposed in Eurocode 2 [42] is used, whereas in the case of FRC-RC sections an extension of the previous formulation proposed by Vandewalle et al. [43] is used.

The steel of the rebars is simulated with the bilinear diagram presented in Fig. 8a.

\section{Basic hypotheses}

The following hypotheses have been considered: (1) perfect bond between the materials; (2) sections remain plane before the application of the external forces or after imposing fixed strains and (3) shear strains are negligible and may not be taken into account.

\section{Equilibrium and compatibility}

Once the suitable constitutive equations have been assigned to each of the materials, a Newton-Raphson iterative method is used to solve the nonlinear equation system resulting from the equilibrium conditions (Eqs. (1) and (2)) and compatibility (Eq. (3)).

$$
\begin{aligned}
& N=\int_{A_{c}} \sigma_{c}\left(\varepsilon_{c}\right) d A_{c}+\sum_{i=1}^{n_{b}} \sigma_{s, i}\left(\varepsilon_{s, i}\right) A_{s, i} \\
& M+N \cdot y_{G}=\int_{A_{c}} \sigma_{c}\left(\varepsilon_{c}\right) \cdot y_{c} d A_{c}+\sum_{i=1}^{n_{b}} \sigma_{s, i}\left(\varepsilon_{s, i}\right) \cdot y_{s, i} A_{s, i}
\end{aligned}
$$


$\varepsilon(y)=\varepsilon_{c, \text { inf }}-y \cdot \chi$

\subsection{Simulation of the tests}

A subroutine included in AES was implemented in order to assess the $\boldsymbol{P}$ - $\boldsymbol{\delta}$ curves considering the test configuration as well as different constitutive equations to simulate the FRC post-cracking behaviour.

The algorithm implemented in the abovementioned tool to obtain the $\boldsymbol{P}$ - $\boldsymbol{\delta}$ laws consists of:

1. Dividing the half span of the slab into intervals of magnitude $\Delta x$ (see Fig. 9a).

2. Obtaining the $M-\chi$ (see Fig. $9 \mathrm{~b}$ ) diagram of the cross section considering the mechanical properties of each material.

3. Fixing an increment of the midspan displacement $\Delta \delta$.

4. Fixing tolerances for the values $\Delta \delta$ and $\Delta P\left(\operatorname{tol}_{\Delta \delta}\right.$ and tol $\mathrm{l}_{\Delta P}$ respectively).

5. Assuming a trial value of the force $\Delta P$.

6. Evaluating the increment of bending forces $\Delta M_{i}$ in each point $x_{i}$ by means of the expression (4).

7. Calculating the accumulated bending force $M_{i}$ in each point $X_{i}$.

8. Finding de bending stiffness $K_{f, i}$ of each section by means of the $M-\chi$ diagram.

9. Solving Eq. (5) (see Appendix A for derivation) in order to obtain $\Delta \delta_{e v}$ (increment of midspan evaluated).

10. Verifying that $\left|\Delta \delta_{e v^{-}} \Delta \delta\right| \leq \operatorname{tol}_{\Delta \delta}$.

11. Returning to the step 5 if the condition of the step 8 is not verified.
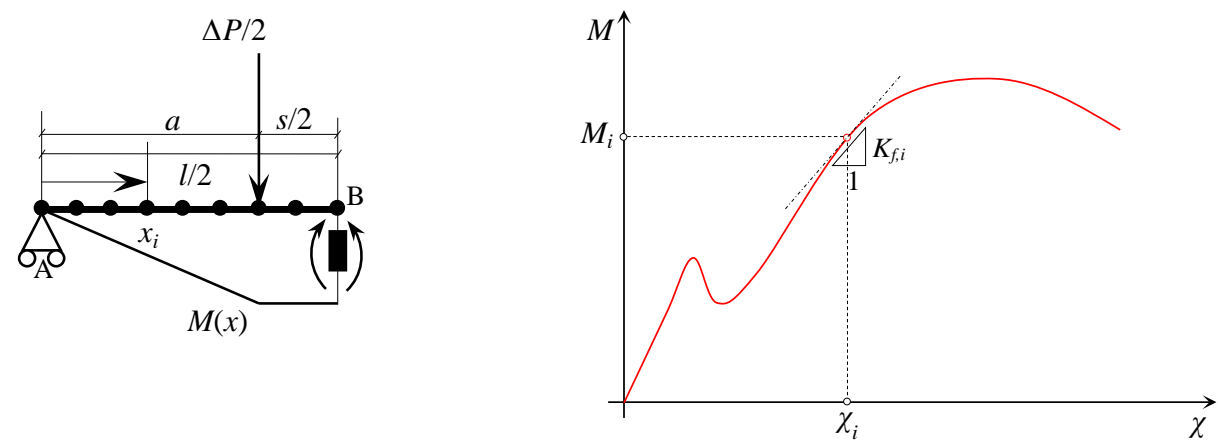

Fig. 9. (a) Discretization of the slab and (b) generic moment-curvature diagram.

$$
\begin{aligned}
& \Delta M= \begin{cases}\frac{\Delta P}{2} x \quad \text { for } 0 \leq x<a \\
\frac{\Delta P}{2} a \quad \text { for } a \leq x<a+\frac{s}{2}\end{cases} \\
& \Delta \delta_{e v}=\Delta P\left[\int_{0}^{a} \frac{l-(2+l) x}{4 K_{f}(x)}\right] d x-\frac{a s}{16 K_{f}(x)_{x=a}}(2 l+4 a+s)
\end{aligned}
$$




\section{Comparison between experimental and numerical results}

\subsection{Methodology}

The numerical simulation was performed considering only the multilinear and the bilinear models due to their higher accuracy in the SLS (see Table 1).

Given that the characterization of the material was performed by means of the 3-point bending test specified in the standard EN14651:2005 [37], it is necessary to correlate this test with the 4-point bending test used in the DBV [2] (DIN1048). Since the test in EN14651:2005 measures the crack mouth opening displacement (CMOD) and the test in DIN1048 [44] measures displacements, these are the two parameters to correlate. In fact, a correlation between EN14651:2005 and NBN 15-238 [45] was already found in [46]. In this case, the correlation will be adapted to the dimensions of the specimen in DIN1048.

The failure mechanisms of the 4-point and 3-point bending test may be schematized as indicated in Fig. 10.

a)

4-point bending test

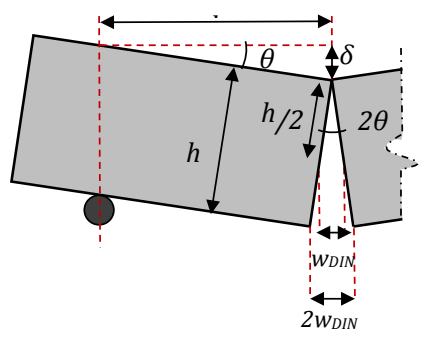

b) 3-point bending test

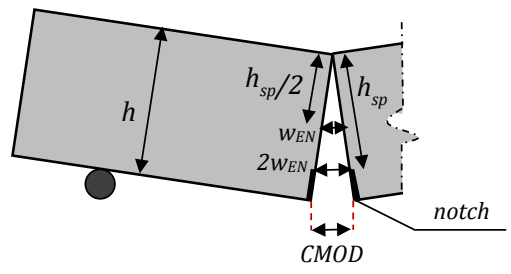

Fig. 10. Failure mechanism of: a) 4-point bending test (unnotched specimen) and b) 3-point bending test (notched specimen).

According to the notation indicated in Fig. 10a, the following equivalences can be deduced for the 4-point bending test:

$$
\begin{gathered}
\theta=\frac{\delta}{l} \\
2 \theta=\frac{2 w}{h} ; \theta=\frac{w}{h}=\frac{w_{D I N}}{h} ;
\end{gathered}
$$

The values of $\boldsymbol{h}$ and $\boldsymbol{l}$ for the specimen in DIN1048 are $150 \mathrm{~mm}$ and $300 \mathrm{~mm}$ (see Table 1 ). The expressions (6) and (7) can be rewritten as:

$$
w_{D I N}=w=\frac{\delta}{2}
$$

Regarding the 3-point bending test, the following equivalences can be made according to Fig. 10b. 


$$
\frac{C M O D}{h}=\frac{2 w}{h_{s p}}=\frac{2 w_{E N}}{h_{s p}} ; w_{E N}=\frac{h_{s p}}{2 h} C M O D
$$

Assuming the average values of crack width for the 4-point bending test ( $\left.w_{\text {DIN }}\right)$ and the 3point bending test $\left(w_{E N}\right)$ are equal for a certain displacement:

$$
\frac{\delta}{2}=\frac{h_{s p}}{2 h} C M O D
$$

Finally, considering the value of $\boldsymbol{h}_{s p}$ is $125 \mathrm{~mm}$ and $\boldsymbol{h}$ is $150 \mathrm{~mm}$ (see Table 1), expression (10) can be rewritten as:

$$
\delta=0.833 C M O D
$$

This correlation can be used to find the equivalence between the experimental results obtained from the test in EN14651:2005 and the results from the test in DIN1048.

For the purpose of this study, it was assumed that the value of the characteristic length equals the experimental average spacing $\left(I_{c s}=s_{r m}\right)$ which are $156 \mathrm{~mm}, 118 \mathrm{~mm}, 138 \mathrm{~mm}$ and $176 \mathrm{~mm}$ for SF_0.25, SF_0.50, PF_0.25 and PF_0.50, respectively.

Additionally, another assumption was made concerning the constitutive model presented in the fib Model Code [6]. In this model, the intersection between the post-cracking branch of the MC90 [47] (which depends on the value of the $\boldsymbol{l}_{\mathrm{cs}}$ ) and the softening branch defined by the parameters in the Model Code 2010 must be obtained (see Fig. 11a). For three of the four experimental cases studied (SF_0.25, PF_0.25 and PF_0.50), the intersection corresponded to a value of strain lower than that for the tensile strength $f_{c t}$. This situation might be associated with the values of $l_{\text {cs }}$ assumed in the study, which in reality could be smaller than the considered in such cases. Since there is no physical sense in having a lower value of strain than that for $f_{c t}$, no contribution of the concrete matrix was considered after the tensile strength was reached in cases SF_0.25, PF_0.25 and PF_0.50 (see Fig. 11b).

a)

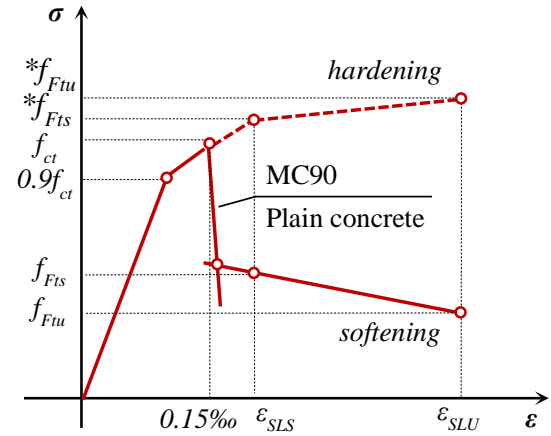

b)

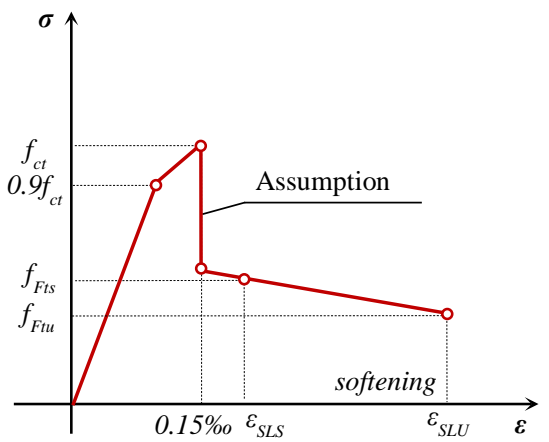

Fig. 11. (a) fib Model Code 2010 and (b) assumption made for some cases.

The value of strain assumed $(0.15 \%)$ is $8 \%, 3 \%$ and $21 \%$ higher than the value obtained by applying the Model Code 2010 for SF_0.25, PF_0.25 and PF_0.50 respectively. The difference in the value of stress is hardly noticeable (in all cases it is inferior to $1 \%$ ).

The numerical results obtained with the model ( $P$ - $\delta$ curves) with the different constitutive models (in the case of RC-FRC slabs) are presented together with the experimental results in subsequent figures. The constitutive models (see Table 1) used for the simulation are also presented. 
The experimental $\boldsymbol{P}-\boldsymbol{\delta}$ curve and the prediction provided by the model AES for the control slab RC are shown in Fig. 12. Additionally, the load values for displacements of $6 \mathrm{~mm}, 15$ $\mathrm{mm}$ and $45 \mathrm{~mm}$, which are representative of different stages of the $\boldsymbol{P}$ - $\boldsymbol{\delta}$ curve, are presented in Table 5.

Fig. 12. Experimental $P$ - $\delta$ curve and prediction for slab $R C$.

\begin{tabular}{cccc}
\hline $\begin{array}{c}\text { Displacement } \\
\text { (mm) }\end{array}$ & \multicolumn{2}{c}{ Load (kN) } & Relative \\
Experimental & Simulation AES & error (\%) \\
\hline 6 & 62.7 & 64.6 & 3.0 \\
15 & 139.4 & 156.4 & 12.2 \\
45 & 214.3 & 210.7 & -1.7 \\
\hline
\end{tabular}

Table 5. RC slab: Load values for displacements of $6 \mathrm{~mm}, 15 \mathrm{~mm}$ and $45 \mathrm{~mm}$ (in $\mathrm{kN}$ ).

The curves in Fig.12 reveal that the prediction of the response for the control slab RC is satisfactory, particularly at the early stages of the loading and after the yielding of the reinforcement occurs. From the results in Table 5, it is observed that for a displacement of $6 \mathrm{~mm}$ the prediction overestimates the experimental results in $3.0 \%$ and for $45 \mathrm{~mm}$ there is an underestimation of only $1.7 \%$. The biggest differences between both curves are detected for values of load over $100 \mathrm{kN}$ and until the yielding of the reinforcement. For example, the prediction for $15 \mathrm{~mm}$ presented in Table 5 is a $12.2 \%$ higher than the load value registered during the test.

\subsection{RC-SFRC slabs}

The constitutive models and the $\boldsymbol{P}-\boldsymbol{\delta}$ curves of the RC-SFRC (SF_0.25 and SF_0.50) are presented in Fig. 13.

Fig. 13. Multilinear diagrams ${ }^{3}$ and $P-\delta$ curves for: $(a-b) S F_{-} 0.25$ and (c-d) $S F_{-} 0.50$; Bilinear diagrams ${ }^{3}$ and $P-\delta$ curves for: ( $e-f) S F_{-} 0.25$ and $(g-h) S F_{-} 0.50$.

The models presented in Fig. 13a and Fig. 13c were conceived to simulate the linearelastic behavior previous to cracking by considering a peak stress and a sudden drop of stress after the cracking. For this reason, a more accurate prediction in SLS is expected. In the case of the RILEM model, considerably high values of peak and post-cracking stresses are adopted if compared to other multilinear models. This difference can lead to an overestimation of the structural response of the element (see $\boldsymbol{P}-\boldsymbol{\delta}$ curves in figures Fig. $13 \mathrm{~b}$ and Fig. 13d). Contrarily, the DBV model presents lower values of residual strength if compared with the RILEM, the EHE and the Model Code, resulting in a conservative prediction of the behavior for large deformations. On the other hand, the EHE and the Model Code overestimate the results for small deformations but for large deformations the prediction remains on the safe side or slightly over the experimental results (see Fig. 13b and Fig. 13d).

In Fig. 13e and Fig. 13g, which correspond to bilinear models, the DBV model also presents the lowest values for residual strengths and, despite fitting satisfactorily the SLS,

${ }_{3} \uparrow$ : Scale change on $\mathrm{x}$-axis. 
the model noticeably underestimates the behavior at ultimate limit state. Even though the CNR-DT 204 and EHE models present the same value for the peak stress, the residual strengths are lower in the case of the CNR-DT 204. This produces a slightly lower response in the failure regime of the simulated slabs if the CNR-DT 204 model is used (see Fig. 13f and Fig. 13h).

Table 6 presents the load values for the slab SF_0.50 corresponding to displacements of 6 $\mathrm{mm}, 15 \mathrm{~mm}$ and $45 \mathrm{~mm}$, which are representative of different stages of the $\boldsymbol{P}$ - $\boldsymbol{\delta}$ curve. It is considered that the load for a displacement of $45 \mathrm{~mm}$ is a good indicative of models that are on the safe side for large deformations close to failure.

\begin{tabular}{llccc}
\hline & Models & $\mathbf{6 ~} \mathbf{~ m m}$ & $\mathbf{1 5} \mathbf{~ m m}$ & $\mathbf{4 5} \mathbf{~ m m}$ \\
\hline Experimental data & Trilinear & 72.9 & 175.1 & 259.8 \\
\hline \multirow{2}{*}{ DBV } & Bilinear & 77.9 & 168.0 & 224.5 \\
\multirow{2}{*}{ RILEM } & Trilinear & 120.6 & 167.7 & 224.5 \\
\hline CNR-DT 204 & Linear-elastic & 107.4 & 250.7 & 259.6 \\
\hline \multirow{2}{*}{ EHE } & Multilinear & 106.7 & 195.9 & 261.3 \\
& Bilinear & 106.8 & 195.5 & 261.8 \\
\hline Model Code & Multilinear & 108.3 & 195.6 & 261.8 \\
\hline
\end{tabular}

Table 6. SF_0.50: Load values for displacements of $6 \mathrm{~mm}, 15 \mathrm{~mm}$ and $45 \mathrm{~mm}$ (in $\mathrm{kN}$ ).

The models that better fit the experimental results in the SLS are the proposed by the DBV. The latter underestimate the load in approximately $6.0 \%$ for $6 \mathrm{~mm}$ and in $4.0 \%$ for $15 \mathrm{~mm}$, while the other models largely overestimate the experimental results: the RILEM 45.5\% and $43.2 \%$, the CNR-DT $20429.6 \%$ and 11.9\%, the EHE 28.8\% and 11.7\%and the Model Code $30.6 \%$ and $12.8 \%$ for $6 \mathrm{~mm}$ and $15 \mathrm{~mm}$, respectively.

When analyzing ULS, the best fits with the experimental results are obtained with the RILEM, the CNR-DT 204, the EHE and the Model Code with a difference of less than $1.6 \%$ with the experimental data. In this sense, the model that presents a larger difference with the experimental result is the DBV trilinear that provides a very conservative prediction (the load for $45 \mathrm{~mm}$ is nearly 14\% lower than those experimentally obtained).

\subsection{RC-PFRC slabs}

The constitutive models and the $\boldsymbol{P}$ - $\boldsymbol{\delta}$ curves of the RC-PFRC slabs (PF_0.25 and PF_0.50) are presented in Fig. 14. It is important to remark that only the CNR-DT 204, the EHE and the Model Code open the range of applicability of their models to other types of fibers appart from steel fibers. However, the basis of knowledge is SFRC, a fact which is reflected in those recommendations.

\footnotetext{
Fig. 14 Mutlilinear diagrams ${ }^{4}$ and $P-\delta$ curves for: ( $\left.a-b\right) P F_{-} 0.25$ and $(c-d) P F_{-} 0.50$; Bilinear diagrams ${ }^{3}$ and $P-\delta$ curves for: ( $\left.e-f\right) P F_{-} 0.25$ and $(g-h) P F_{-} 0.50$.
}

The analysisis of Fig. 14a and Fig. 14c shows that the RILEM model presents a higher value of peak stress, as in the case of steel fibers. Instead, the DBV presents the lowest values, resulting in a conservative structural response of the element for large deformations. The $\boldsymbol{P}-\boldsymbol{\delta}$ curves obtained with each of the multilinear models are shown in figures Fig. 14b and Fig. 14d. It must be highlighted the accuracy of the models in reproducing the behaviour of both slabs (PF_0.25 and PF_0.50). In this case, the fit is even

\footnotetext{
${ }_{4}$ V: Scale change on $\mathrm{x}$-axis.
} 
better than with SF. The accuracy of these models to reproduce the change in the stiffness of the material after cracking may be observed in Fig. 14b and Fig. 14d for small displacements.

The bilinear models in Fig. 14e and Fig. 14g show that the DBV model give again the lowest values for residual strength. The lower residual strengths proposed by the CNR-DT 204 in comparison with the EHE results in a slightly lower response in the $\boldsymbol{P}$ - $\boldsymbol{\delta}$ curve for large deformations, as shown in Fig. 14f and Fig. 14h. In spite of that, the accuracy of the bilinear models in the prediction of the experimental results is very satisfactory in all cases.

The load values for displacements of $6 \mathrm{~mm}, 15 \mathrm{~mm}$ and $45 \mathrm{~mm}$ are presented for the slab PF_0.50 in Table 7.

\begin{tabular}{|c|c|c|c|c|}
\hline \multicolumn{2}{|l|}{ Models } & $6 \mathrm{~mm}$ & $15 \mathrm{~mm}$ & $45 \mathrm{~mm}$ \\
\hline \multicolumn{2}{|c|}{ Experimental data } & 75.7 & 156.1 & 232.0 \\
\hline \multirow{2}{*}{ DBV } & Trilinear & 70.4 & 160.6 & 215.8 \\
\hline & Bilinear & 69.3 & 161.2 & 215.6 \\
\hline RILEM & Trilinear & 80.1 & 167.7 & 224.8 \\
\hline CNR-DT 204 & Linear-elastic & 77.2 & 167.6 & 223.1 \\
\hline \multirow{2}{*}{ EHE } & Trilinear & 77.7 & 167.8 & 224.2 \\
\hline & Bilinear & 77.3 & 167.7 & 224.3 \\
\hline Model Code & Multilinear & 79.0 & 168.7 & 225.7 \\
\hline
\end{tabular}

Table 7. PF_0.50: Load values for displacements of $6 \mathrm{~mm}, 15 \mathrm{~mm}$ and $45 \mathrm{~mm}$ (in $\mathrm{kN}$ ).

The results indicate that the models which better reproduce the experimental data for small deflections ( $6 \mathrm{~mm}$ ) are the CNR-DT 204 and the EHE, with errors below 2\%. At this level of deflection, the DBV models underestimate the response of the slabs though this difference is relatively small (around 8\%). The RILEM and the Model Code overestimate the experimental results and present the largest differences. For larger deflections (15 $\mathrm{mm}$ ) this tendency changes and the two DBV models present the best fit, with an overestimation of 3\%. In this case, the RILEM, CNR-DT 204 and the EHE provide an almost identical prediction of the experimental data. The overestimation of these models is approximately $7.4 \%$. In this case, the largest overestimation of the experimental data is found if the Model Code is used (8.1\%).

Nevertheless, the model providing the prediction closest to the experimental data for large displacements ( $45 \mathrm{~mm}$ ) is the Model Code, with a $2.7 \%$ underestimation of the response measured. At this deflection the RILEM, the CNR-DT 204 and the EHE present similar results, underestimating the response of the slabs in 3.5\% approximately. The DBV presents the most conservative prediction with an underestimation around $7.0 \%$.

The analysis of the variations between experimental and predicted results indicates that the constitutive models considered may provide satisfactory predictions of the mechanical response of the slabs simulated in this paper.

\section{Conclusions}

The most relevant consitituve models from the literature were analyzed and compared in terms of their capacity to predict the structural response of FRC. From the comparative analysis conducted in this study, the following conclusions may be drawed. 
- The conceptual basis for the constitutive models comes from studies and experimental programs conducted with steel fibers. Nevertheless, this does not prevent the application of these recommedations to plastic fibers with good results.

- The models included in the DBV present a different approach if compared with the models from other guidelines. In all cases, the DBV models (trilinear and bilinear) provide a very conservative prediction, remaining on the safe side for both steel fibers and polypropylene fibers. This is especially noticeble for large displacements.

- The estimations performed with the constitutive model from the RILEM differ significatively from the experimental results for small displacements.

Nevertheless, the estimations reproduce accurately the experimental results for large displacements.

- The models proposed in the CNR-DT 204 and in the EHE provide almost identical predictions as a result of their similarity. Both models present a satisfactory estimation of the response for both small and large deformations. The latter usually remains on the safe side.

- Likewise, the updated Model Code predicts satisfactorily the structural response for both types of fibers at small and large displacements.

Currently, there is a significant basis upon which to build and promote FRC technology. Despite the different approaches proposed to address the tensile behavior of FRC, the efforts of the most recent guidelines to gather and assimilate the experience gained through the years are remarkable. The Model Code deserves a special mention since this model seeks to lay the foundations for a single technical framework and serve as a document of reference for future standards and recommendations.

\section{Acknowledgements}

The authors of this document wish to show their gratitude for the economic support received through the Research Project BIA2010-17478: Construction processes by means of fibre reinforced concretes. The first and second authors acknowledge the grant FI provided by the Comissionat per a Universitats del DIUE de la Generalitat de Catalunya i del Fons Social Europeu and the Grant FPI-UPC provided by the UPC, respectively. The first and second authors also acknowledge the support of the Col-legi d'Enginyers de Camins, Canals i Ports de Catalunya.

\section{References}

[1] di Prisco M, Plizzari G, Vandewalle L. Fibre reinforced concrete: new design perspectives, Mater Struct 2009; 42(9):1261-1281.

[2] DBV Merkblatt Stahlfaserbeton, Deutsche Beton Vereins, 2001.

[3] RILEM TC 162-TDF. Test and design methods for steel fibre reinforced concrete - $\sigma-\varepsilon$ design method: Final Recommendation, Mater Struct 2003; 36(262):560-567.

[4] CNR-DT 204. Istruzioni per la Progettazione, l’Esecuzione ed il Controllo di Strutture Fibrorinforzato, Consiglio Nazionale delle Riserche, Italia, 2006.

[5] Comisión Permanente del Hormigón (Ministerio de Fomento), EHE-08 Instrucción del Hormigón Estructural, 2008.

[6] fib. Model Code 2010, Comité Euro-International du Beton-Federation International de la Precontrainte, Paris, 2010.

[7] de la Fuente A, Pujadas P, Blanco A, Aguado A. Experiences in Barcelona with the use of steel fibres in segmental linings, Tunn Undergr Sp Tech 2011; 7(1):60-71. 
[8] Tiberti G, Plizzari GA, Walraven JC, Blom CBM. Concrete tunnel segments with combined traditional and fiber reinforcement, In: Walraven JC, Stoelhorst D, editors. Tailor Made Concrete Structures, London: Taylor\&Francis Group; 2008, p. 199-205.

[9] Molins C, Arnau O. Experimental and analytical study of the structural response of segmental tunnel linings based on an in situ loading test. Part 1: Test configuration and execution, Tunn Undergr Sp Techn 2011, 26(6):764-777.

[10] Haktanir T, Ari K, Altun F, Karahan O. A comparative experimental investigation of concrete, reinforced-concrete and steel-concrete pipes under three-edge-bearing test. Constr Build Mater 2007; 21(8):1702-1708.

[11] de la Fuente A, Escariz RC, Figueiredo AD, Molins C, Aguado A. A new design method for steel fibre reinforced concrete pipes. Constr Build Mater 2012; 30:547-555.

[12] Chiaia B, Fantilli AP, Vallini P. Evaluation of crack width in FRC structures and application to tunnel linings, Mater Struct 2009, 42(3):339-351.

[13] Pujadas P, Blanco A, de la Fuente A, Aguado A. Cracking behavior of FRC slabs with traditional reinforcement, Mater Struct 2012, 45(5):707-725.

[14] de la Fuente A, Figueiredo AD, Aguado A, Molins C, Chama Neto PJ. Experimentation and numerical simulations of steel fibre reinforced concrete pipes, Mater Construcc 2011; 61(302):275-288.

[15] Laranjeira F. Design-oriented constitutive model for steel fiber reinforced concrete, $\mathrm{PhD}$ Thesis, Universitat Politècnica de Catalunya; 2010.

[16] Hillerborg A, Modéer M, Petersson P. Analysis of crack formation and crack growth in concrete by means of fracture mechanics and finite elements, Cem Con Res 1976; 6:773-780.

[17] Bazant ZP, Oh BH. Crack band theory for fracture of concrete, Mater Struct 1983; 16:155-177.

[18] Foote R, Mai YW, Cotterell B. Process size and crack growth measurements in fibre cements. Fibre reinforced concrete properties and applications, American Concrete Institute, Detroit; 1985. p. 55-70.

[19] Hu X, Wittmann FH. Experimental method to determine extension of fracture-process zone, J Mater Civ Eng 1990; 2(1):15-23.

[20] Lim TY, Paramsivam P, Lee SL. Bending Behaviour of Steel-Fiber Concrete Beams, ACI J 1987; 84:286-298.

[21] Elsaigh WA, Robberts JM, Kearsley EP. Modelling non-linear behaviour of steel fibre reinforced concrete, In: Proceedings of Sixth RILEM Symposium on Fibre-Reinforced Concretes (BEFIB 2004), Varenna, Italy; 2004. p. 837-846.

[22] Lok TS, Xiao L. Tensile behaviour and moment-curvature relationship of steel fibre reinforced concrete, Mag Concrete Res 1998; 50(4):359-368.

[23] Dupont D, Vandewalle L. Characterisation of steel fibre concrete with a $\sigma-\varepsilon$ relation, In: Proceedings of the $4^{\text {th }}$ International PhD Symposium in Civil Engineering, Munich, Germany; 2002. p. 108-114.

[24] Kooiman AG. Modelling Steel Fibre Reinforced Concrete for Structural Design, PhD Thesis, Delft University of Technology; 2000.

[25] Barragán BE. Failure and toughness of steel fiber reinforced concrete under tension and shear, $\mathrm{PhD}$ thesis, Universitat Politècnica de Catalunya; 2002.

[26] di Prisco M, Ferrara L, Colombo M, Mauri M. On the identification of SFRC constitutive Law in uniaxial tension, Proceedings of Sixth RILEM Symposium on Fibre-Reinforced Concretes (BEFIB 2004), Varenna, Italy; 2004. p. 827-836.

[27] Dozio D. SFRC structures: Identification of the uniaxial tension characteristic constitutive law, PhD Thesis, Politecnico de Milano; 2008.

[28] Li VC, Stang H, Krenchel H. Michromechanics of crack bridging in fiber reinforced concrete, Mater Struct 1993; 26(162):486-494.

[29] Prudencio L, Simon A, Jones P, Armelin H, Robins P. Prediction of steel fibre reinforced concrete under flexure from an inferred fibre pull-out response, Mater Struct 2006; 39(6):601610.

[30] Jones PA, Austin SA, Robins PJ. Predicting the flexural load-deflection response of steel fibre reinforced concrete from strain, crack width, fibre pull-out and distribution data, Mater Struct 2008, 41(3):449-463.

[31] Luccioni B, Ruano G, Isla F, Zerbino R, Giaccio G. A simple approach to model SFRC, Constr Build Mater 2012; 37:111-124.

[32] Soranakom C, Mobasher B. Flexural design of fiber-reinforced concrete, ACI Mater J 2009; 105(5):461-469 
[33] Walraven, J.C. High performance fiber reinforced concrete: progress in knowledge and design codes, Mater Struct 2009; 42(9):1247-1260.

[34] Blanco A, Pujadas P, de la Fuente A, Aguado A. Análisis comparativo de los modelos constitutivos del hormigón reforzado con fibras, Hormigón y Acero 2010; 61(256):83-100.

[35] Barros JAO, Cunha VMCF, Ribeiro AF, Antunes JAB. Post-cracking behaviour of steel fibre reinforced concrete, Mater Struct 2005; 38(1):47-56.

[36] Vandewalle L, di Prisco M, Plizzari G. Fiber Reinforced Concrete in the New FIB Model Code, In: Proceedings of Codes in Structural Engineering - Developments and Needs for International Practice, Dubrovnik, Croatia; 2010: 1325-1332. SECON - CSSE.

[37] EN 14651:2005. Test method for metallic fibrered concrete - Measuring the flexural tensile strength (limit of proportionality (LOP), residual), CEN 2005.

[38] EN 12390-3:2009. Testing hardened concrete. Compressive strength of test specimens, CEN 2009.

[39] Parmentier B, De Grove E, Vandewalle L, Van Rickstal F. Dispersion of the mechanical properties of FRC investigated by different bending tests, In: Walraven JC, Stoelhorst D, editors. Tailor Made Concrete Structures, London: Taylor\&Francis Group; 2008, p. 507-512.

[40] Molins C, Aguado A, Saludes S. Double Punch Test to control the energy dissipation in tension of FRC (Barcelona test), Mater Struct 2009; 42(4):415-425.

[41] Barros JAO, Figueiras JA. Flexural behaviour of SFRC: Testing and modelling, J Mater Eng 1999; 11(4):331-339.

[42] ENV 1992-1-1/2005. Eurocode 2: Design of concrete structures - Part 1-1: General rules and rules for buildings. CE.

[43] Vandewalle L. Cracking behaviour of concrete beams reinforced with a combination of ordinary reinforcement and steel fibers, Mater Struct 2000, 33(3):164-170.

[44] DIN1048. Prüfverfahren für Beton; Teil 1: Frischbeton; Festbeton in Bauwerken und Bauteilen, DIN 1991.

[45] NBN B 15-238. Essais des bétons renforcés de fibres - Essai de flexion sur éprouvettes prismatiques, IBN 1992.

[46] Monsó A. Análisis del comportamiento del hormigón reforzado con fibras para el ensayo Barcelona y de flexotracción, Minor Thesis, Universitat Politècnica de Catalunya; 2011.

[47] CEB-FIP. Model Code 1990: Design code. Thomas Telford Services Ltd, Lausanne, 1993.

\section{Appendix A. Derivation of the expressions (5)}

The rotation in $\mathrm{A}\left(\Delta \varphi_{A}\right)$ is evaluated by means of the first theorem of Mohr (A.1) and the increment of displacement in the midspan $\Delta \delta_{B}$ by means of the second one (A.2):

$$
\begin{aligned}
& \Delta \varphi_{B}=\Delta \varphi_{A}+\int_{0}^{a+\frac{s}{2}} \frac{\Delta M(x)}{K_{f}(x)} d x \\
& \Delta \delta_{B}=\Delta \delta_{A}+\Delta \varphi_{A} \frac{l}{2}+\int_{0}^{a+\frac{s}{2}} \frac{\Delta M(x)}{K_{f}(x)}\left(\frac{l}{2}-x\right) d x
\end{aligned}
$$

The values of $\Delta \varphi_{B}$ and $\Delta \delta_{A}$ are zero due to the symmetry condition.

Likewise, substituting (d) in (A.1) and in (A.2), the following relations (A.3) and (A.4) are obtained:

$$
\begin{aligned}
& 0=\Delta \varphi_{A}+\int_{0}^{a} \frac{\Delta P}{2 K_{f}(x)} x d x+\int_{a}^{a+\frac{s}{2}} \frac{\Delta P}{K_{f}(x)} a d x \\
& \Delta \delta_{B}=\Delta \varphi_{A} \frac{l}{2}+\int_{0}^{a} \frac{\Delta P(x)}{2 K_{f}(x)} x\left(\frac{l}{2}-x\right) d x+\int_{0}^{a+\frac{s}{2}} \frac{\Delta P}{2 K_{f}(x)} a\left(\frac{l}{2}-x\right) d x
\end{aligned}
$$


Integrating the expressions (A.3) and (A.4), and designating $K_{f}(x=a)=K_{a}$, the values of $\Delta \varphi_{A}$ and $\Delta \delta$ expressed in function of both the unknown $\Delta P$ and the bending stiffness (A.5 and A.6, respectively) are obtained.

$\Delta \varphi_{A}=-\frac{\Delta P}{4}\left[2 \int_{0}^{a} \frac{x}{K_{f}(x)} d x+\frac{a s}{K_{a}}\right]$

$\Delta \delta_{B}=\Delta \varphi_{A} \frac{l}{2}+\frac{\Delta P}{4}\left[\int_{0}^{a} \frac{l}{K_{f}(x)} d x+\frac{a s}{4 K_{a}}(2 l-4 a-s)\right]$

Then, substituting (A.5) in (A.6) a final relation between $\Delta \delta_{B}$ and $\Delta P$ is derived (A.7).

$\Delta \delta_{B}=\frac{\Delta P}{4}\left[\int_{0}^{a} \frac{\xi(x)}{K_{f}(x)} d x-\frac{a s}{4 K_{a}}(2 l-4 a-s)\right]$

where:

$\xi(x)=l-(2+l) x$

Finally, the analytical expression (A.7) is solved iteratively by using (A.9):

$$
\Delta \delta_{B}^{k+1}=\frac{\Delta P^{k+1}}{4}\left\{\left[\frac{\xi(0)}{K_{f}(0)}+\sum_{i=1}^{n_{p}-1} \frac{\xi\left(x_{i}\right)}{K_{f}\left(x_{i}\right)}+\frac{\xi(a)}{K_{f}(a)}--\frac{a s}{4 K_{a}}(2 l-4 a-s)\right]\right\}
$$

